\title{
ROASTED CASHEW NUT KERNEL (ANACARDIUM OCCIDENTALE L.) SUPPLEMENTATION IMPROVES HEPATIC AND RENAL STATUS BUT NOT LIPID PROFILE IN RATS
}

\author{
ADEMOLA C FAMUREWA ${ }^{1 *}$, INNOCENT ABI ${ }^{2}$, EMMANUEL U ERU ${ }^{2}$ \\ ${ }^{1}$ Department of Medical Biochemistry, Faculty of Basic Medical Sciences, Federal University, Ndufu-Alike Ikwo, Ebonyi State, Nigeria. \\ ${ }^{2}$ Department of Physiology, Benue State University, Makurdi, Benue State, Nigeria. Email: clementademola@yahoo.com
}

Received: 30 December 2016, Revised and Accepted: 27 January 2016

\section{ABSTRACT}

Objective: Although studies suggest that nut consumption is associated with a variety of beneficial health outcomes, however, there is a dearth of data in the literature to document this effect for roasted cashew nut kernel (RCNK). Our objective was to determine whether dietary consumption of RCNK could improve lipid profile, hepatic and renal status in rats.

Methods: A total of 24 rats were randomly divided into four groups: A control and three experimental groups fed with roasted cashew nutsupplemented diet at different concentrations for 28 consecutive days. After the experimental period, rats were anesthetized with ether and retroorbital blood samples were withdrawn. Serum samples were obtained to analyze lipid profile, markers of oxidative stress, hepatic and renal status using standard methods.

Results: The supplemented diet significantly decreased the liver function parameters in rats. All the concentrations of RCNK in diets significantly reduced serum creatinine and urea levels. However, total cholesterol and low-density lipoprotein-cholesterol (LDL-C) were significantly increased, whereas oxidative stress markers and malondialdehyde were improved by the supplemented diet, although insignificantly, as compared with the control.

Conclusions: These results suggest that RCNK may have beneficial health effects on the liver and kidney status although marked improvement was not demonstrated in oxidative stress markers. However, the significant increase in serum total and LDL-C indicates the need for further studies.

Keywords: Roasted cashew nut, Anacardium occidentale, Lipid profile, Liver enzymes, Oxidative stress.

(C) 2016 The Authors. Published by Innovare Academic Sciences Pvt Ltd. This is an open access article under the CC BY license (http://creativecommons. org/licenses/by/4. 0/) DOI: http://dx.doi.org/10.22159/ajpcr.2016.v9i5.10510

\section{INTRODUCTION}

Nut consumption is an important source of nutrition and increasingly consumed for health benefits in different climes of the world. Nuts are dry fruits with one seed in which the ovary wall becomes hard at maturity [1]. They are reported to be nutrient-dense foods with complex matrices rich in monounsaturated fatty acids (MUFA) and polyunsaturated fatty acids, dietary fibers, high-quality proteins, micronutrients, magnesium, potassium, arginine, and bioactive phytochemicals [1-3]. The popular edible nuts such as almonds, Brazil nuts, hazelnuts, walnuts, peanuts, pecans, pistachios, kola nuts, and cashew nuts are consumed by humans, although individual intake varies remarkably [4]. Epidemiological findings indicate that frequent nut consumption offers protection from fatal and non-fatal cardiovascular disease events, reduction in the risk of chronic diseases and improvement in body weight gain $[3,4]$. Studies have associated nut consumption with several health benefits and demonstrated its antioxidant, hypocholesterolemic, anticancer, antiobesity, antiinflammatory and antidiabetic effects, among other functional properties mediated by several different mechanisms $[2,4,5]$.

Cashew nut (Anacardium occidentale L.), the heart-like fruit of the family Anacardiaceae, plays an important role in human diets as an edible nut worldwide. It is native to Brazil, and introduced about two centuries ago to Goa, India, which became one of the major producers of cashew nuts, accounting for almost $50 \%$ of the total world export [6], with commercial recognition being observed in other developing countries, including Indonesia and some African countries [6]. The kernels of cashew nuts are rich in lipids (42.6\%), proteins (20.0\%), and fiber (5.9\%) and comprised $575 \mathrm{kcal}$ of energy per $100 \mathrm{~g}$ [7]. In addition, $100 \mathrm{~g}$ of edible cashew provide $3.96 \mathrm{~g}$ of sugar, $2.82 \mathrm{mg}$ of vitamin $\mathrm{B}$, $37 \mathrm{mg}$ of calcium, $292 \mathrm{mg}$ of magnesium, $593 \mathrm{mg}$ of phosphorus, and $660 \mathrm{mg}$ of potassium [7]. Recently, the antioxidant activities of various bioactive compounds such as phenolics, flavonoids, phospholipids, sphingolipids, sterols, and tocopherols were reported in cashew nut samples [7]. The cashew nut is roasted over open fires or in red hot charcoal in most Nigerian rural communities to obtain the nutritious kernel from the tough shell and consumed in large quantities all year round [8]. During the process, the cashew nut becomes crunchy and brittle leading to an overall increased taste, flavor, sensory qualities, and palatability [9].

However, some reports have associated conventional shelling methods with the loss of heat-sensitive bioactive compounds in cashew nut kernel $[6,10,11]$, as previous studies suggest that processing method may affect nutritional quality and health benefits of foods [9,12]. To our knowledge, there is a paucity of data on the association of roasted cashew nut kernel (RCNK) with health benefits through dietary consumption. Although a line of evidence suggests that nut consumption may beneficially impact on health outcomes $[1,2,4,13]$, recent observations indicate that health benefits from nut consumption may be contextually specific, depending on the type of nut consumed [13]. For instance in the previous studies, the beneficial health impacts of consumption of walnut, almonds and peanut have been associated with improvement in glycemic control, plasma lipid profile, lipid peroxidation markers, diabetes, risk of colorectal cancer, and cardiovascular diseases [14-18], whereas the unsalted cashew nut intervention diets had no significant effect on lipid profile, serum fructosamine, serum high-sensitivity C-reactive protein, blood pressure, and serum uric acid concentrations when compared with the control diet [3]. The nuts most frequently studied have been almonds and walnuts. Currently, studies on the health impact of consumption of RCNK are scarce in scientific literature, although studies on composition analysis reported beneficial nutritional profile $[6,8,9]$. The assessment of the possible health effects of RCNK consumption will enhance and provide evidence for its importance in diet. This 
study, therefore, investigated the effect of RCNK on lipid profile, oxidative stress markers, hepatic and renal status in rats

\section{METHODS}

\section{Chemicals and reagents}

All chemicals and reagents used were of analytical grade. Commercial reagent kits for the determination of serum lipid profile, alanine aminotransferase (ALT), aspartate aminotransferase (AST), urea, creatinine, and enzyme makers of oxidative stress were supplied by Randox Diagnostic Laboratory, Crumlin, UK. 2-thiobarbituric acid (TBA) was obtained from Sigma Chemicals Co. (Taufkirchen, Germany). Diethyl ether was supplied by Guanghua Chemical Factory Co., Ltd. China.

\section{Experimental animals}

A total of 24 Wistar albino rats of either sex weighing 120-140 g were obtained from the Animal House, Biochemistry Department, University of Nigeria, Nsukka and acclimatized for 1 week in a wellventilated experimental room of the Department of Biochemistry, Ebonyi State University, Abakaliki before the experiment. The animals were housed in metal cages and maintained under standard environmental conditions with a range temperature $21-23^{\circ} \mathrm{C}$ and photoperiod of $12 \mathrm{hrs}$ light/12 hrs dark cycle with free access to normal rat chow and clean water. Handling of animals was in accordance with the relevant institutional and ethical guidelines as approved for scientific study.

\section{RCNK}

RCNK was purchased from the commercial sellers and ground manually to the size of normal rat feed to enhance homogeneity and free consumption of the supplemented diet.

\section{Experimental design}

After the acclimatizing period, animals were randomly segregated into four different groups of six animals each. The control group was fed with a normal rat chow; Group 2 fed with 10\% RCNK supplemented diet; Group 3 fed with $20 \%$ RCNK supplemented diet, while Group 4 was fed with $30 \%$ RCNK supplemented diet $(w / w)$. The normal rat chow and RCNK were mixed until there was homogeneity and served to the animals ad libitum. The preparation of the supplemented diet was done on regular demand. Before the consumption of the diet, initial weight of rats in control and experimental groups was determined and recorded. The rats were exposed to daily consumption of the supplemented diet for 28 consecutive days. After the experimental period, final weights of rats were taken and recorded. All the groups of rats were fasted overnight and subjected to mild diethyl ether anesthesia on day 29. Blood was quickly withdrawn via retro-orbital puncture into clean plain tubes. The blood was allowed to stand for 35 minutes and then centrifuged at $3500 \mathrm{rpm}$ for 15 minutes to obtain serum. The sera were separated and stored (at $-20^{\circ} \mathrm{C}$ ) until biochemical analyses.

\section{Biochemical analyses}

Serum lipid profile, ALT, AST, superoxide dismutase (SOD), glutathione peroxidase (GPx) activities, urea, and creatinine were estimated with commercially available kits from Randox Laboratories Ltd. (Crumlin, UK) via spectrophotometer, model SPM721 (Biotrust Diagnostics Inc., USA). Catalase (CAT) activity was determined by the method of Sinha [19]. Lipid peroxidation product, malondialdehyde (MDA) was estimated spectrophotometrically by measuring TBA-reactive substances, as described by Wallin et al. [20].

\section{Statistical analysis}

The data were expressed as mean \pm standard error of means based on the indicated number in the experiment $(\mathrm{n}=6)$. A statistical analysis was performed with SPSS 17.0 for windows. The differences between the means of data were compared by one-way ANOVA test followed by Tukey's test. The differences were considered significant at $\mathrm{p}<0.05$.

\section{RESULTS}

\section{Body weight change}

At the end of the 28 days, change in body weight was significantly higher $(p<0.05)$ in animals that consumed supplemented diets in comparison to control group (Table 1).

\section{Lipid profile}

The serum lipid profile parameters are shown in Table 2. The daily consumption of the diet by rats demonstrated non-significant ( $p>0.05$ ) concentration-dependent increases in triglyceride. Similar trends were observed for total cholesterol (TC) and low-density lipoproteincholesterol (LDL-C), although with significant increases $(\mathrm{p}<0.05)$ in rats fed with $10 \%$ and $30 \%$ RCNK diets as compared to control. However, the supplemented diets (20\% and 30\% RCNK) decreased high-density lipoprotein-cholesterol (HDL-C) non-significantly as compared to control.

\section{Liver and kidney status}

Table 3 presents the effect of the diet on markers of the liver and kidneys status. The diet decreased the serum markers of the liver and kidney status in this study. Markers of the liver status, AST and ALT activities were found to be significantly decreased $(\mathrm{p}<0.05)$ by $10 \%$ RCNK and 20\% RCNK diets, respectively. Moreover, all supplemented diets significant decreased serum levels of urea and creatinine $(p<0.05)$.

\section{Oxidative stress and lipid peroxidation}

Table 4 shows that the diets had no significant effect on SOD, CAT, and GPx in the current study. Although we observed some increases in serum levels of these markers of oxidative stress (SOD and GPx) but not significantly different $(p>0.05)$ when compared with control. Lipid peroxidation marker, MDA, decreased with the diet but only significantly $(\mathrm{p}<0.05)$ for the treatment with $20 \%$ RCNK.

\section{DISCUSSION}

Numerous studies have provided evidence that nuts constitute a good source of vital nutritional compounds that could elicit beneficial outcomes in health and disease $[1,4]$. However, emerging evidence indicates that the beneficial effects may depend on the type of nut consumed [13]. Cashew nut is rarely studied in association with health

\section{Table 1: Effects of RCNK-supplemented diet on body weight of rats}

\begin{tabular}{lllll}
\hline Parameter & Control & $\mathbf{1 0 \%}$ RCNK & $\mathbf{2 0 \%}$ RCNK & $\mathbf{3 0 \% ~ R C N K}$ \\
\hline $\begin{array}{l}\text { Initial body } \\
\text { weight (g) }\end{array}$ & $120.0 \pm 6.37$ & $138.6 \pm 4.20$ & $128.1 \pm 9.53$ & $136.2 \pm 5.81$ \\
$\begin{array}{l}\text { Final body } \\
\text { weight (g) }\end{array}$ & $149.8 \pm 6.62$ & $181.4 \pm 6.52$ & $174.2 \pm 15.08$ & $180.6 \pm 8.70$ \\
$\begin{array}{l}\text { Weight } \\
\text { change (g) }\end{array}$ & $28.4 \pm 3.17$ & $42.8 \pm 3.73^{*}$ & $40.9 \pm 6.91$ & $44.5 \pm 3.02 *$ \\
\hline
\end{tabular}

Values are mean \pm SEM $(n=6)$. *Values with superscripts in the same column differ significantly $(\mathrm{p}<0.05)$ from the control. SEM: Standard error of mean, RCNK: Roasted cashew nut kernel

Table 2: Effect of RCNK-supplemented diet on lipid profile of rats (mmol/L)

\begin{tabular}{lllll}
\hline Treatment & Triglyceride & TC & LDL-C & HDL-C \\
\hline Control & $1.90 \pm 0.09$ & $2.77 \pm 0.11$ & $2.38 \pm 0.79$ & $1.77 \pm 0.14$ \\
$10 \%$ RCNK & $1.83 \pm 0.14$ & $2.73 \pm 0.19$ & $4.30 \pm 0.14^{\text {a }}$ & $1.78 \pm 0.17$ \\
$20 \%$ RCNK & $2.02 \pm 0.05$ & $2.93 \pm 0.15$ & $3.52 \pm 0.71$ & $1.60 \pm 0.19$ \\
$30 \%$ RCNK & $2.04 \pm 0.09$ & $3.06 \pm 0.07^{\text {a }}$ & $4.46 \pm 0.42^{\text {a }}$ & $1.74 \pm 0.42$ \\
\hline
\end{tabular}

Values are mean \pm SEM $(n=6)$. Values with superscripts in the same column differ significantly $(p<0.05)$ from the control. SEM: Standard error of mean, RCNK: Roasted cashew nut kernel, TC: Total cholesterol, LDL-C: Low-density lipoprotein-cholesterol, HDL-C: High-density lipoprotein-cholesterol 
Table 3: Effect of RCNK-supplemented diet on markers of liver and kidney status of rats

\begin{tabular}{lllll}
\hline Treatment & AST (U/L) & ALT (U/L) & $\begin{array}{l}\text { Urea } \\
\text { (mg/dl) }\end{array}$ & $\begin{array}{l}\text { Creatinine } \\
\text { (mg/dl) }\end{array}$ \\
\hline Control & $73.7 \pm 10.16$ & $107.0 \pm 21.05$ & $50.8 \pm 6.65$ & $1.64 \pm 0.11$ \\
$10 \%$ RCNK & $43.5 \pm 5.32^{\mathrm{a}}$ & $95.5 \pm 20.76$ & $21.0 \pm 4.04^{\mathrm{a}}$ & $0.91 \pm 0.07^{\mathrm{a}}$ \\
$20 \% \mathrm{RCNK}$ & $51.0 \pm 3.62$ & $60.0 \pm 6.76^{\mathrm{a}}$ & $44.67 \pm 9.39$ & $1.28 \pm 0.09^{\mathrm{a}}$ \\
$30 \% \mathrm{RCNK}$ & $48.8 \pm 5.09$ & $66.2 \pm 7.74$ & $40.6 \pm 10.63$ & $1.14 \pm 0.04^{\mathrm{a}}$ \\
\hline
\end{tabular}

Values are mean \pm SEM $(n=6)$. Values with superscripts in the same column differ significantly $(\mathrm{p}<0.05)$ from the control. SEM: Standard error of mean, RCNK: Roasted cashew nut kernel, ALT: Alanine aminotransferase, AST: Aspartate aminotransferase

Table 4: Effect of RCNK-supplemented diet on markers of oxidative stress and MDA in rats

\begin{tabular}{lllll}
\hline Treatment & $\begin{array}{l}\text { SOD } \\
(\mathbf{U} / \mathbf{m l})\end{array}$ & $\begin{array}{l}\text { CAT } \\
(\mathbf{U} / \mathbf{m l})\end{array}$ & GPx $(\mathbf{U} / \mathbf{m l})$ & $\begin{array}{l}\text { MDA } \\
(\mathbf{m g} / \mathbf{m l})\end{array}$ \\
\hline Control & $11.20 \pm 0.12$ & $2.73 \pm 0.34$ & $30.57 \pm 7.23$ & $1.96 \pm 0.06$ \\
$10 \%$ RCNK & $11.41 \pm 0.19$ & $3.03 \pm 0.25$ & $42.85 \pm 7.92$ & $1.74 \pm 0.03$ \\
$20 \%$ RCNK & $11.29 \pm 0.07$ & $2.07 \pm 0.19$ & $54.72 \pm 11.86$ & $1.47 \pm 0.25^{\mathrm{a}}$ \\
$30 \%$ RCNK & $11.19 \pm 0.14$ & $2.38 \pm 0.16$ & $48.56 \pm 13.85$ & $1.85 \pm 0.05$ \\
\hline
\end{tabular}

Values are mean \pm SEM $(n=6)$. Values with superscripts in the same column differ significantly $(p<0.05)$ from the control. SEM: Standard error of mean, RCNK: Roasted cashew nut kernel, SOD: Superoxide dismutase, CAT: Catalase, GPx: Glutathione peroxidase, MDA: Malondialdehyde

benefits, in spite of its robust antioxidant and fatty acid profiles $(21.6 \%$ saturated fatty acid and $78.1 \%$ unsaturated fatty acid) reported [21]. To our knowledge, however, very little research has been done on cashew and limited data are currently available on the beneficial role of RCNK in biological system.

In this context, the present experimental study evaluates whether dietary consumption of RCNK could improve lipid profile, hepatic and renal status in rats. As deciphered by the present investigation, the dietary treatments improve the liver and kidney status but not lipid profile in albino rats. Our results showed that at the end of the $4^{\text {th }}$ week, there was a statistically significant increase in body weight gain when the RCNK-supplemented diet groups were compared to control (Table 1). This could be due to an increase in diet consumption by rats which may be caused by increased palatability, taste and flavor associated with RCNK [9]. However, some studies found that long-term consumption of nuts is associated with reduced risk of weight gain and obesity $[4,22]$. Although our study was done in experimental animals and specifically in RCNK, our findings suggest that different nuts may have different effects on health indices as reported by a previous study [13].

In previous studies, walnut and almonds - the frequently studied nuts provide evidence that nut diet displays beneficial cholesterol-lowering effect usually without any significant effect on triglycerides or HDL-C in healthy subjects [23]. In this study, RCNK seems to increase lipoprotein cholesterol including triglyceride although some increases were not statistically remarkable. Of note in this study is the $10 \%$ and $30 \%$ RCNK-supplemented diets that significantly increase TC and LDL-C levels without favorable improvement in HDL-C levels (Table 2). This is in agreement with two separate studies that used diet high in cashew or walnut $[3,24]$ compared to control diets in obese patients with the metabolic syndrome that failed to show a significant effect on the TC, LDL-C, and HDL-C levels. In contrast, a study reported beneficial effect of cashew nut on lipoprotein cholesterol and triglyceride [25]. Earlier studies have reported that roasting of cashew nut may reduce bioactive compounds and exhibits increase in total fats and fatty acids $[6,9]$. For example, Kosoko et al. [9] reported significant increases in total fats and fatty acids in open pan and halogen oven RCNK when compared with unprocessed cashew nut kernel. Heating is known to adversely affect fatty acids [26], although an important fraction of fat contained in most nuts is MUFA, which is not a substrate for oxidation [1]. However, the fatty acids may be affected by heating, a practice common in cashew nut processing, which may increase susceptibility to lipid oxidation that deteriorates the quality of dietary oils and fats [26], and this may be important for cholesterol levels observed in this study.

Our study demonstrated beneficial impact of the supplemented diet on the liver and kidney status. The activities of serum AST and ALT are the most sensitive biomarkers that indicate hepatic damage and toxicity. Elevation of AST has been reported to be an index of hepatocellular injury in rats, while ALT elevation is more associated with the necrotic state [27]. In this study, the $10 \%$ and $20 \%$ RCNK diet treatments induced the opposite effect and markedly reduced the serum levels of AST and ALT. These findings demonstrate the non-toxic and membrane stabilizing potential of the RCNK. Although we observed non-significant increases in antioxidant enzyme activities, they may play a positive role in the beneficial outcome associated with the kernel on hepatocytes. Similarly, serum creatinine and urea levels were significantly decreased in every group treated with supplemented diet. Marked elevations of serum creatinine and urea concentration are known as markers of significant functional impairment of kidney, although serum creatinine concentration is a more potent indicator than urea in the first phase of kidney injury $[28,29]$. Limited data are currently available on RCNK, and we found no study that evaluated consumption of cashew nut for the liver and kidney health.

Our study showed that MDA levels were decreased while SOD, CAT, and GPx levels were increased insignificantly in the serum. In physiological condition, endogenous generation of reactive oxygen species (ROS) could rapidly be detoxified by antioxidant enzymes including SOD and CAT. Walnut and Brazil nuts have been shown to contribute to a significantantioxidant effectin experimental rats and disease conditions, including hypertension [30-32]. Analysis of the effects of cashew nut in the diet on antioxidant status of human subjects with metabolic syndrome resulted in an increased antioxidant capacity [24]. The 28 days of cashew kernel consumption show insignificant improvement in serum antioxidant system, however, it is not known whether longterm consumption of RCNK would demonstrate significant antioxidant effect against ROS damage and generation of MDA, an indicator of free radical generation and end-product of lipid peroxidation. As suggested by earlier studies [9-12], the bioactive compound profile might have been reduced in the roasted cashew nut by the roasting method, and this may account for the observation of non-significant antioxidant effect in this study.

\section{CONCLUSION}

This study has shown the beneficial effects of RCNK on the liver and kidney status, although marked improvement was not demonstrated in oxidative stress markers. However, the supplemented diets contributed significantly to increase serum cholesterol levels with important health implications. The potential health benefits or harms of nuts may depend on the type of nut consumed. Nevertheless, future research on roasted cashew nut is worthy of exploration.

\section{REFERENCES}

1. Ros E. Health benefits of nut consumption. Nutrients 2010;2(7):652-82

2. Brufau G, Boatella J, Rafecas M. Nuts: Source of energy and macronutrients. Br J Nutr 2006;96 Suppl 2:S24-8.

3. Mukuddem-Petersen J, Stonehouse Oosthuizen W, Jerling JC, Hanekom SM, White Z. Effects of a high walnut and high cashew nut diet on selected markers of the metabolic syndrome: A controlled feeding trial. Br J Nutr 2007;97(7):1144-53.

4. Vadivel V, Kunyanga CN, Biesalski HK. Health benefits of nut consumption with special reference to body weight control. Nutrition 2012;28(11-12):1089-97.

5. Ros E, Mataix J. Fatty acid composition of nuts - Implications for cardiovascular health. Br J Nutr 2006;96 Suppl 2:S29-35.

6. Trox J, Vadivel V, Vetter W, Stuetz W, Scherbaum V, Gola U, et al. Bioactive compounds in cashew nut (Anacardium occidentale L.) 
kernels: Effect of different shelling methods. J Agric Food Chem 2010;58(9):5341-6.

7. Chandrasekara N, Shahidi F. Antioxidative potential of cashew phenolics in food and biological model systems as affected by roasting. Food Chem 2011;129:1388-96.

8. Nnorom CI, Ewuzie U. Mineral constituents of roasted cashew nuts (Anacardium occidentale L.) from Southeastern Nigeria. IOSR J Environ Sci Toxicol Food Technol 2013;6(4):13-21.

9. Kosoko SB, Oluwole OB, Daramola AO, Adepoju MA, Oyelakin AJ, Tugbobo-amisu AO, et al. Comparative quality evaluation of roasted cashew nut kernel: Effect of roasting methods. Adv J Food Sci Technol 2014;6(12): 1362-71.

10. Jain SK, Powar AG, Kad VP, Dandekar SR, Salvi DA, Dekale JS Effect of direct steam roasting on organoleptic properties of cashew-nut kernels. Cashew 2004;18:20-4.

11. Mandal RC. Cashew production and processing technology. In: Singh RP, Srivastava P, editors. Post-Harvest Processing of Food Grains. India: Agro-Botanical Publishers; 1992. p. 146-8.

12. Singh S, Gamlath S, Wakeling L. Nutritional aspects of food extrusion: A review. Int J Food Sci Technol 2007;2:916-29.

13. Sun Y, Jiang CQ, Cheng KK, Zhang WS, Leung GM, Lam TH, et al. Nut consumption and cardiovascular risk in older Chinese: The Guangzhou biobank cohort study. PLoS One 2015;10(9):e0137178.

14. Feldman EB. The scientific evidence for a beneficial health relationship between walnuts and coronary heart disease. J Nutr 2002;132(5):1062S-101.

15. Li TY, Brennan AM, Wedick NM, Mantzoros C, Rifai N, Hu FB. Regular consumption of nuts is associated with a lower risk of cardiovascular disease in women with type 2 diabetes. J Nutr 2009;139(7):1333-8

16. Yeh CC, You SL, Chen CJ, Sung FC. Peanut consumption and reduced risk of colorectal cancer in women: A prospective study in Taiwan. World J Gastroenterol 2006;12(2):222-7.

17. Jenkins DJ, Kendall CW, Marchie A, Josse AR, Nguyen TH, Faulkner DA, et al. Almonds reduce biomarkers of lipid peroxidation in older hyperlipidemic subjects. J Nutr 2008;138(5):908-13.

18. Li SC, Liu YH, Liu JF, Chang WH, Chen CM, Chen CY. Almond consumption improved glycemic control and lipid profiles in patients with type 2 diabetes mellitus. Metabolism 2011;60(4):474-9.

19. Sinha AK. Colorimetric assay of catalase. Anal Biochem 1972;47(2):389-94.

20. Wallin B, Rosengren B, Shertzer HG, Camejo G. Lipoprotein oxidation and measurement of thiobarbituric acid reacting substances formation in a single microtiter plate: Its use for evaluation of antioxidants. Anal Biochem 1993;208(1):10-5

21. Ogungbenle HN, Afolayan MF. Physical and chemical characterization of roasted cashew nut (Anacardium occidentale) flour and oil. Int J Food Sci Nutr Eng 2015;5(1):1-7.

22. Bes-Rastrollo M, Wedick NM, Martinez-Gonzalez MA, Li TY, Sampson L, Hu FB. Prospective study of nut consumption, longterm weight change, and obesity risk in women. Am J Clin Nutr 2009;89(6):1913-9.

23. Sabaté J, Fraser GE, Burke K, Knutsen SF, Bennett H, Lindsted KD. Effects of walnuts on serum lipid levels and blood pressure in normal men. N Engl J Med 1993;328(9):603-7.

24. Davis L, Stonehouse W, Loots du T, Mukuddem-Petersen J, van der Westhuizen FH, Hanekom SM, et al. The effects of high walnut and cashew nut diets on the antioxidant status of subjects with metabolic syndrome. Eur J Nutr 2007;46(3):155-64.

25. Asdaq SM, Malsawmtluangi C. Evaluation of anti-obesity potential of cashew nut (Anacardium occidentale) in animals. Indian J Pharm Sci Res 2015;5(1):42-50.

26. Ng CY, Leong XF, Masbah N, Adam SK, Kamisah Y, Jaarin K. Reprint of "heated vegetable oils and cardiovascular disease risk factors". Vascul Pharmacol 2014;62(1):38-46.

27. Adesanoye OA, Farombi EO. Hepatoprotective effects of Vernonia amygdalina (Astereaceae) in rats treated with carbon tetrachloride. Exp Toxicol Pathol 2010;62(2):197-206.

28. Tavafi M, Ahmadvand $\mathrm{H}$. Effect of rosmarinic acid on inhibition of gentamicin induced nephrotoxicity in rats. Tissue Cell 2011;43(6):392-7.

29. Tirkey N, Pilkhwal S, Kuhad A, Chopra K. Hesperidin, a citrus bioflavonoid, decreases the oxidative stress produced by carbon tetrachloride in rat liver and kidney. BMC Pharmacol 2005;5:2.

30. Reiter RJ, Manchester LC, Tan DX. Melatonin in walnuts: Influence on levels of melatonin and total antioxidant capacity of blood. Nutrition 2005;21(9):920-4.

31. Cominetti C, de Bortoli MC, Purgatto E, Ong TP, Moreno FS, Garrido $\mathrm{AB} \mathrm{Jr}$, et al. Associations between glutathione peroxidase-1 Pro198Leu polymorphism, selenium status, and DNA damage levels in obese women after consumption of Brazil nuts. Nutrition 2011;27(9):891-6.

32. Huguenin GV, Oliveira GM, Moreira AS, Saint' Pierre TD, Gonçalves RA, Pinheiro-Mulder AR, et al. Improvement of antioxidan status after Brazil nut intake in hypertensive and dyslipidemic subjects. Nutr J 2015;14:54. 